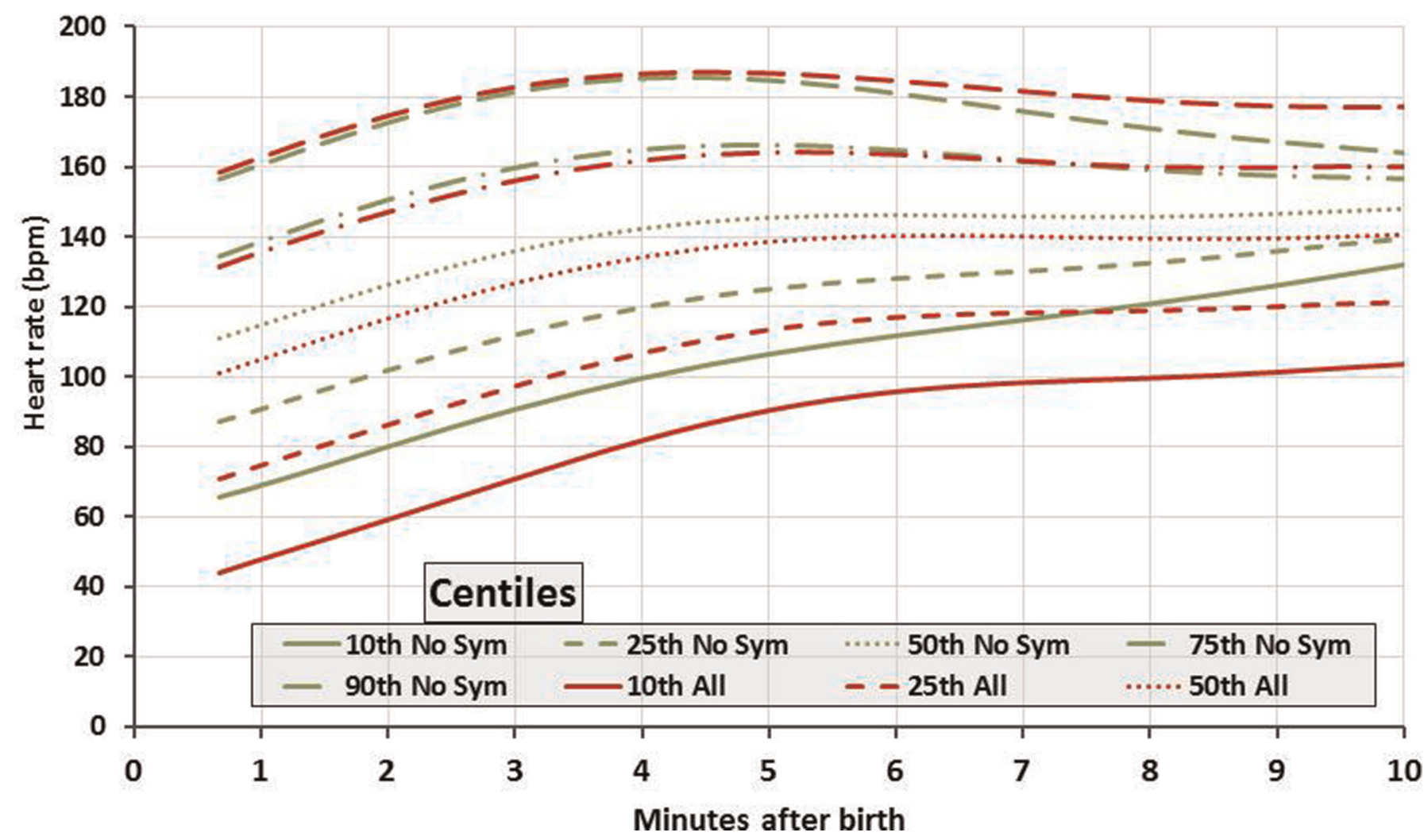

Abstract 0-067 Figure 3 Centile charts for heart rate for all signals and no-SyM signals 10th, 25th, 50th, 75th, and 90th centile for heart rate for all signals in red and for signals without system message (no-SyM) in green

\section{0-068 VISUAL INTERVAL TIMER SIGNIFICANTLY IMPROVES ACCURACY OF HEART RATE ASSESSMENT DURING NEWBORN RESUSCITATION SIMULATIONS: A RANDOMISED STUDY}

A Pereira, R Janes, D Morris, D Sharkey. Academic Child Health - School of Medicine, University of Nottingham, Nottingham, UK

\subsection{6/archdischild-2014-307384.136}

Introduction Heart rate (HR) assessment, performed using a stethoscope, is the most useful measure of the need for and effectiveness of newborn resuscitation. However, it is incorrect in approximately $30 \%$ of cases (Voogdt 2010). We hypothesised a 6 second flashing device would increase HR accuracy during simulated newborn resuscitation.

Methods Newborn Life Support (NLS) qualified healthcare professionals undertook simulated newborn resuscitation. Using a

Abstract 0-068 Table 1
\begin{tabular}{|c|c|c|c|c|}
\hline $\begin{array}{c}\text { Heart } \\
\text { Rate }\end{array}$ & $\begin{array}{c}\text { Own method } \\
\text { n (\%) }\end{array}$ & $\begin{array}{c}6 s \text { Timer } \\
\text { n (\%) }\end{array}$ & n & P value \\
\hline 50 & $4(9 \%)$ & $2(5 \%)$ & 44 & NS \\
\hline 70 & $14(32 \%)$ & $6(14 \%)$ & 44 & $P=0.04$ \\
\hline 90 & $41(47 \%)$ & $18(21 \%)$ & 88 & $P=0.0004$ \\
\hline 110 & $16(36 \%)$ & $6(14 \%)$ & 44 & $P=0.03$ \\
\hline Total & $75(34 \%)$ & $32(15 \%)$ & 220 & $P<0.0001$ \\
\hline
\end{tabular}

randomised crossover design, participants were allocated to calculate random HRs with a stethoscope using either their own preferred method or a 6 second flashing timer (count HR multiple by 10). Accuracy (within $10 \mathrm{bpm}$ ) and assessment time were compared. Ethical approval was granted.

Results 44 NLS trained participants performed 440 HR assessments. HR accuracy improved significantly from $16.2 \mathrm{bpm}$ (own method, 95\% CI 13.7-18.7) to $10.7 \mathrm{bpm}$ (timer, 95\% CI 8.213.2) (see Table). HR assessment time decreased significantly from $22.6 \mathrm{~s}$ (own method) to $14.7 \mathrm{~s}$ (timer) $(\mathrm{p}<0.0001)$. When categorising the HR into NLS categories (HR $>100,60-100$ and $<60 \mathrm{bpm})$ participants were incorrect using their own method $31 \%$ of the time compared to $16 \%$ with the timer $(\mathrm{p}<0.0001)$. When resuscitating the baby for 5 cycles of the recommended algorithm only 4 (9\%) participants did this without error using their own method compared to $23(52 \%)$ using the timer.

Conclusions Use of a simple 6 second visual timer significantly increases accuracy of HR assessment during newborn resuscitation simulations and reduces overall time of assessment. Integration of such a timer into the stethoscope head or resuscitaire could be a simple and inexpensive method to improve newborn resuscitation.

\section{0-069 MASK VENTILATION WITH TWO DIFFERENT FACEMASKS DURING POSITIVE PRESSURE VENTILATION IN THE DELIVERY ROOM: A RANDOMISED CONTROLLED TRIAL}

${ }^{1} \mathrm{DC}$ Cheung, ${ }^{1} \mathrm{Q}$ Mian, ${ }^{1} \mathrm{~A}$ Hudson-Mason, ${ }^{1} \mathrm{~K}$ Aziz, ${ }^{2} \mathrm{M}$ O'Reilly, ${ }^{1} \mathrm{PY}$ Cheung, ${ }^{1} \mathrm{GM}$ Schmolzer. 'Neonatal Research Unit, Royal Alexandra Hospital, Edmonton, Canada; ${ }^{2}$ Pediatrics, University of Alberta, Edmonton, Canada 
Background and aims If infants fail to initiate spontaneous breathing after birth, international guidelines recommend positive pressure ventilation (PPV). However, mask PPV remains challenging with leakage occurring commonly. Despite a variety of available facemasks, none has been systemically studied in newborn infants. We aimed to determine if using a Fisher and Paykel (FP) round facemask would reduce mask leak compared to using a Laerdal round facemask during mask PPV in preterm infants.

Methods From April to September 2013, at the Royal Alexandra Hospital, newborn infants.

Results Fifty-eight preterm infants ( $\mathrm{n}=29$ in each group) were enrolled; mean \pm SD gestation $28 \pm 3$ weeks; birth weight 1210 $\pm 448 \mathrm{~g}, 30(52 \%)$ male, 39(67\%) born by caesarean section. Apgar scores at 1 and 5 min were $5 \pm 3$ and $7 \pm 2$, respectively. Infants randomised to the FP facemask and Laerdal facemask had similar mask leak ( $37 \pm 17 \%$ vs. $33 \pm 12 \%$, respectively, p $=0.30)$ and tidal volume $(7.3 \pm 3.0 \mathrm{~mL} / \mathrm{kg}$ vs. $6.9 \pm 2.7 \mathrm{~mL} /$ $\mathrm{kg}, \mathrm{p}=0.73$ ) during PPV. There were no significant differences in ventilation rate, inflation time or airway pressures between groups.

Conclusions The use of either facemask during PPV in the delivery room yields similar mask leak.

\section{0-069a VIDEOLARYNGOSCOPY AS AN INTUBATION TRAINING TOOL FOR NEONATAL TRAINEES - A RANDOMISED CONTROLLED TRIAL}

J O'Shea, M Thio, COF Kamlin, L McGrory, J Jubal, C Roberts, C Kuschel, PG Davis. Department of Newborn Research, Royal Women's Hospital, Melbourne, Australia

\subsection{6/archdischild-2014-307384.138}

Background and aims Endotracheal intubation is a mandatory skill for neonatal trainees. However, inexperienced trainees have success rates $<50 \%$. We compared intubations supervised by an instructor watching a videolaryngoscope screen with the traditional method where the instructor does not have this view.

Methods RCT (ANZCTR\# 12613000159752) at The Royal Women's Hospital, Melbourne. Eligible intubations were those performed orally, in infants without facial or airway anomalies, in the delivery room or in NICU, by trainees with $<6$ months experience. Intubations were randomised to videolaryngoscope screen visible to the instructor (intervention) or covered (control). Primary outcome was first attempt intubation success rate confirmed by colorimetric detection of expired $\mathrm{CO}_{2}$. A sample size of 206 provided $80 \%$ power to detect a $20 \%$ difference in success rates $(50 \%$ vs. $70 \%)$.

\begin{tabular}{|c|c|c|c|}
\hline & Control $(n=102)$ & Intervention $(n=104)$ & $\mathbf{P}$ \\
\hline Corrected gestation $(w)^{*}$ & $29(27-32)$ & $29(27-32)$ & 0.82 \\
\hline Weight $(g)^{*}$ & $1125(816-1569)$ & 1172.5 (819-1884) & 0.35 \\
\hline Success rate $-\mathrm{n}(\%)$ & $42 / 102(41.2 \%)$ & $69 / 104(66.3 \%)$ & $<0.001$ \\
\hline \multicolumn{4}{|l|}{ Success rate with } \\
\hline premedication - n (\%) & $35 / 79(44.3 \%)$ & $56 / 78(71.8 \%)$ & $<0.001$ \\
\hline \multicolumn{4}{|l|}{ Success rate without } \\
\hline premedication - n (\%) & $7 / 23(30.4 \%)$ & $13 / 26(50 \%)$ & 0.164 \\
\hline Lowest $\mathrm{SpO}_{2}(\%)^{*}$ & $69(46-82)$ & $70(47.5-83)$ & 0.88 \\
\hline Lowest heart rate $(\mathrm{bpm})^{*}$ & $151(139-162)$ & $150(134.5-163.5)$ & 0.99 \\
\hline Duration of attempt $(s)^{*}$ & $53(41-70)$ & $51(39-63)$ & 0.15 \\
\hline
\end{tabular}

Results

Conclusions Intubation success rates of inexperienced doctors were significantly improved, OR 2.81 (95\% CI 1.54-5.17), when the instructor was able to share their view on a videolaryngoscope screen.

\section{Nephrology I}

\section{0-070 HAEMODYNAMIC IMPACT OF THE CONNECTION OF CONTINUOUS RENAL REPLACEMENT THERAPY IN CRITICALLY ILL CHILDREN}

B Toledo, MJ Santiago, SN Fernández, M García, AC Sánchez, J Del Castillo, J López-Herce. PICU, Hospital General Universitario Gregorio Marañón, Madrid, Spain

\subsection{6/archdischild-2014-307384.139}

Background Continuous Renal Replacement Therapies (CRRT) are the treatment of choice for critically ill children with Acute Renal Injury. Hypotension after starting CRRT is frequent but there are no studies that have analysed their incidence and importance.

Patients and methods A prospective, observational study was performed including critically ill children treated with CRRT between October 2009 and December 2013. Hemodynamic data and connection characteristics were collected before, during and $60 \mathrm{~min}$ after CRRT circuit connection. Hypotension with the connection was defined as a decrease in mean arterial pressure $>20 \%$ from baseline and/or intravenous fluid expansion and/or if increase in vasopressors was required.

Results 161 connections in 36 children (median age 18.8 months) were analysed. 28 patients $(77.8 \%)$ were in the postoperative period of cardiac surgery, $94 \%$ on mechanical ventilation and $86.1 \%$ with vasopressors. The circuit prime was discarded in $8.7 \%$ of connections, the heparinised prime was infused in $18 \%$ and the circuit was previously primed witha colloid (albumin in $77.5 \%$ ) or crystalloid without heparine in $73.3 \%$. Hypotension occurred in $49.7 \%$ of connections with a median of 5 min after the beginning. In $38.5 \%$ of the connections fluid expansion was required and in $12.4 \%$ vasopressors were increased. There was no hypotension relation to age or weight. Previous priming of the circuit reduced the frequency of hypotension to $44.6 \%$ vs. $71.4 \%$ ( $p=0.004)$.

Conclusions Hypotension after CRRT connection is very frequent in critically ill children. Priming the circuit improves hemodynamic tolerance of the connection.

\section{0-071 SALT-SPARING DIURETIC ACTION OF A UREA ANALOGUE INHIBITOR OF UREA TRANSPORTERS UT-A AND UT-B IN RATS}

${ }^{1} \mathrm{O}$ Cil, ${ }^{2} \mathrm{C}$ Esteva-Font, ${ }^{3} \mathrm{ST}$ Tas, ${ }^{2} \mathrm{~S}$ Lee, ${ }^{3} \mathrm{M}$ Ertunc, ${ }^{2} \mathrm{AS}$ Verkman. ${ }^{1}$ Depatment of Pediatrics, Hacettepe University, Faculty of Medicine, Ankara, Turkey; ${ }^{2}$ Departments of Medicine and Physiology, University of California San Francisco, San Francisco, USA; ${ }^{3}$ Depatment of Pharmacology, Hacettepe University, Faculty of Medicine, Ankara, Turkey

\subsection{6/archdischild-2014-307384.140}

Background and aims Urea is end metabolite of protein metabolism and is crucial for generation of hypertonic renal medulla. Urea transport to medullary interstitium is facilitated by urea transporters (UT-A and UT-B). UT inhibitors have potential use as a novel class of salt-sparing diuretics.

Methods UT inhibitor effect of urea analogue dimethylthiourea (DMTU) was investigated and characterised in cell-based assays. 